\section{A) Check for updates}

Cite this: Food Funct., 2021, 12, 8850

\title{
Fruits and their impact on the gut microbiota, gut motility and constipation
}

\author{
Zoi Katsirma, Eirini Dimidi, (D) Ana Rodriguez-Mateos (D) and Kevin Whelan (D)*
}

Fruits are the seed-bearing product of plants and have considerable nutritional importance in the human diet. The consumption of fruits is among the dietary strategies recommended for constipation due to its potential effects on the gut microbiota and gut motility. Dietary fiber from fruits has been the subject of research on the impact on gut microbiota, gut motility and constipation, however, fruits also contain other components that impact the intestinal luminal environment that may impact these outcomes including sorbitol and (poly)phenols. This review aims to explore the mechanisms of action and effectiveness of fruits and fruit products on the gut microbiota, gut motility and constipation, with a focus on fiber, sorbitol and (poly)phenols. In vitro, animal and human studies investigating the effects of fruits on gut motility and gut microbiota were sought through electronic database searches, hand searching and consulting with experts. Various fruits have been shown to modify the microbiota in human studies including blueberry powder (lactobacilli, bifidobacteria), prunes (bifidobacteria), kiwi fruit (Bacteroides, Faecalibacterium prausnitzii) and raisins (Ruminococcus, F. prausnitzii). Prunes, raisins and apple fiber isolate have been shown to increase fecal weight in humans, whilst kiwifruit to increase small bowel and

Received 12th April 2021, Accepted 23rd August 2021

DOI: $10.1039 / \mathrm{d} 1$ fo01125a

rsc.li/food-function fecal water content. Apple fiber isolate, kiwifruit, fig paste, and orange extract have been shown to reduce gut transit time, while prunes have not. There is limited evidence on which fruit components play a predominant role in regulating gut motility and constipation, or whether a synergy of multiple components is responsible for such effects.

\section{Introduction}

Constipation is a symptom-based bowel disorder, characterized by difficult, infrequent or incomplete bowel movements. ${ }^{1}$ Constipation can be acute (duration of less than a week) or chronic (duration of more than 3 months) ${ }^{2}$ and based on the etiology it is categorized by the Rome IV criteria into two subtypes: functional constipation and constipation-predominant irritable bowel syndrome (IBS-C). ${ }^{3}$ Both types can be impacted by impaired gut transit time (slow-transit constipation), and evacuation disorders may also be present. ${ }^{2}$ Constipation can be either primary or secondary, with the latter resulting from underlying conditions or pharmacological therapies. ${ }^{4,5}$ The focus of this review will be primary, functional constipation. Functional constipation is defined according to the Rome IV criteria as the presence of at least two of the following symptoms for at least $25 \%$ of defecations and lasting for at least 3 months: fewer than 3 defecations per week; hard or lumpy stools; straining; a sense of incomplete evacuation; a sensation

Department of Nutritional Sciences, King's College London, 150 Stamford Street, SE1 9NH London, UK. E-mail: kevin.whelan@kcl.ac.uk of anorectal obstruction; or the need for manual maneuvers to assist defecation. This diagnosis also requires loose or watery stools to be rare and the person not meeting the Rome IV criteria for irritable bowel syndrome. ${ }^{3}$

The global prevalence of constipation is $14 \%{ }^{6}$ A cohort study of almost 500 general practitioners who reviewed medical records of over 3 million patients in the United Kingdom (UK), showed that 12.8 per 1000 people had a diagnosis of constipation by their general practitioner, ${ }^{7}$ however this likely underestimates the prevalence of constipation, as many affected individuals do not consult a healthcare professional. ${ }^{8}$ The economic cost of chronic constipation to patients and the health system is substantial and various studies in the United States (US) and Europe have attempted to quantify it. ${ }^{9-12}$ In the US, total cost was \$235 million per year (2006 data), ${ }^{12}$ while the annual constipation-related healthcare costs per person was as high as $\$ 11991$, with almost half attributed to outpatient services (2010 data). ${ }^{10}$ In England, the National Health Service spent $£ 168$ million on constipation treatment in 2018-2019, split between the cost of prescribed laxatives and constipation-related hospital admissions. ${ }^{11}$ In Romania, the annual national expenditure on prescribed or over the counter laxatives was calculated at 15 million euros. ${ }^{9}$ 
Risk factors for chronic constipation include older age, the female sex, lack of physical activity, low energy intake and other factors such as dieting, low fiber intake, fluid depletion, number of medications, low income and education level, clinical depression or a history of physical and sexual abuse. ${ }^{13}$ Constipation has also been linked to an altered gut microbiota compared to healthy controls. ${ }^{14-17}$

Chronic constipation affects quality of life. ${ }^{4,18}$ Constipation also results in lower stool weight compared with healthy individuals,$^{19}$ and low stool weight (average of 5 or more days) has been associated with an increased risk of colorectal cancer, with an incidence rate ratio of 1.49 (95\% CI, 1.26-1.76) in males and 1.67 (95\% CI, 1.45-1.93) in females. ${ }^{20}$ However, other observational studies have suggested that the link between constipation and increased risk of colorectal cancer is attributed to non-fiber laxatives, ${ }^{21}$ whose use is common among constipation patients. ${ }^{22}$ However, another observational study did not show that such an association. ${ }^{23}$ These observations of high economic cost, impact on quality of life and potentially increased risk of colorectal cancer highlight the importance of successfully preventing and managing constipation, ${ }^{24}$ and it has been suggested that the goal is global relief of constipation symptoms and return to normal bowel function, ${ }^{25}$ yet decreasing the risk of serious constipationassociated cancer should also be a public health goal.

Dietary modification is part of the primary approach in the treatment of constipation. The World Gastroenterology Association recommends an increase in fiber intake either by dietary advice or through supplementation. ${ }^{26}$ In the UK, guidance for health professionals suggest the recommendation for the consumption of fruits including those that are rich in sorbitol, giving examples such as apricots, peaches and plums, as well as their corresponding juices. ${ }^{27}$ National recommendations provided to the general public highlight the importance of lifestyle and dietary modifications, with a particular focus on ensuring adequate hydration and increasing the consumption of fiber-rich foods, such as whole grains, vegetables and fruits. ${ }^{27,28}$ Some fruits are perceived to have stool softening abilities, with a survey of 1088 participants, including healthy individuals and patients with constipation or IBS-C, reporting prunes to be the most stool softening. ${ }^{29}$ However, there is limited evidence regarding the mechanisms of action of fruits towards gut motility and constipation, and few studies have addressed their effectiveness in impacting gut transit time and reducing constipation symptoms in clinical trials. The aim of this review is to discuss the existing evidence on the effects of fruits on gut microbiota, gut motility and constipation, with a focus on the mechanisms of action and effectiveness.

\section{Materials and methods}

This narrative review focused on in vitro and animal studies, human clinical trials, and systematic reviews where available. Electronic database searches were performed on Ovid
(MEDLINE, Embase) using Medical Subject Headings (MeSH) relevant to each concept of interest, applying the necessary truncations and Boolean operators: (("constipat*" OR ("bowel" OR "gut" OR intestin*")) AND ("function" OR "health" OR "physiology" OR "microbiome" OR "microbiota") AND ("fiber" OR "fibre" OR "polyphenol*" OR "sorbitol" OR "fruit*" OR "juice" OR "extract*")). Relevant publications were also discovered through back searching reference lists from eligible publications, hand searching and recommendations from experts in the field. Studies including mechanistic outcomes (e.g. microbiome, gastrointestinal transit time, fecal output, gut $\mathrm{pH}$, fecal water content) were included.

\section{Fruit components, gut microbiota, gut motility and constipation}

Fruits are the seed-bearing product of plants and have considerable nutritional importance in the human diet. Fruits in their fresh, dried or juiced form are a rich source of some vitamins, minerals and dietary fiber ${ }^{30-32}$ and are a core component of the World Health Organization '5-a-day' fruit and vegetable recommendation. ${ }^{33}$

Dietary fiber has been the subject of much research on the impact on gut microbiota, gut motility and constipation, however, fruits contain several other components that may impact the intestinal lumen environment and they will be discussed below. ${ }^{34-39}$

\section{Dietary fiber}

Several fruits are excellent sources of dietary fiber. ${ }^{30}$ Fiber is defined as the sum of carbohydrates that are polymers of three or more monomeric units and are not digested or absorbed in the small intestine, plus lignins. ${ }^{40}$ Fiber is not one molecule, but a range of molecules that vary in solubility, viscosity and fermentability. ${ }^{41}$ Non-fermentable fibers reach the lower gut intact, whilst viscous fibers have a higher water-binding ability, and therefore both are potent in bulking stool. ${ }^{42}$ An increase in stool bulk further causes luminal distention and triggers peristalsis. ${ }^{43}$ Fermentable fibers increase gut microbiota abundance and therefore fecal biomass and increase short-chain fatty acid (SCFA) production. This results in an increased colonic osmotic load which increases the water content of the feces ${ }^{44}$ leading to softer stools. Several publications have reported that various high-fiber foods lead to reductions in whole gut transit time. ${ }^{45-48}$

\section{Sorbitol}

Sorbitol is a sugar alcohol found in plants. Sorbitol is not digested or absorbed in the small intestine ${ }^{49}$ and has the ability to hold water in its molecules, ${ }^{50}$ leading to the increase of water in the gut lumen, which could soften stools and therefore ease defecation. In a randomized controlled trial (RCT), $40 \mathrm{~g}$ per day sorbitol for 6 days resulted in significantly greater fecal water and fecal weight compared to placebo. ${ }^{39}$ Furthermore, unabsorbed sorbitol reaches the colon where it is fermented by the gut microbiota, increasing SCFA production, ${ }^{51}$ and possibly altering the microbiota. While this 
hypothesis has not been tested in humans, sorbitol in rats increased fecal, colonic and cecal Lactobacillus sp. AD102 and fecal $L$. reuteri compared to fructo-oligosaccharides and control, as well as higher butyrate in colonic and cecal samples compared to control. ${ }^{52}$

\section{(Poly)phenols}

(Poly)phenols are a large class of chemical compounds present in plant foods and beverages, including fruits, vegetables, grains, tea, coffee and wine. ${ }^{53,54}$ Their structure consists of one or more hydroxyl groups bonded to an aromatic hydrocarbon group.

Only a small proportion of low-molecular-weight (poly) phenols are absorbed in the small intestine while those of a higher molecular weight reach the colon unaffected, ${ }^{55}$ where they become available for fermentation by the gut microbiota, which breaks larger (poly)phenols into smaller, absorbable molecules, potentially responsible for numerous health benefits. $^{56}$ Moreover, existing evidence suggests that (poly) phenols have the potential to positively modify the gut microbiota by either increasing bacteria known to be helpful for the maintenance of gut health such as Bifidobacterium and Lactobacillus, or by inhibiting the growth of potentially pathogenic bacteria. ${ }^{57-62}$ While it has been hypothesized that due to their anti-inflammatory abilities (poly)phenols may be beneficial in the treatment of inflammatory bowel disease or irritable bowel syndrome, ${ }^{60}$ there are currently not enough data to show a direct effect on constipation.

\section{Fiber, sorbitol and (poly)phenols in fruits and fruit products}

Fiber, sorbitol and (poly)phenols are the main constituents that mediate the effect of fruits on gut microbiota, gut motility and gut function and therefore might impact constipation. Different fruits contain varying amounts of fiber, sorbitol and (poly)phenols, while the processing of fruit can have major impacts on these. For example, fresh or dried fruits, fruit pulps or whole-fruit smoothies (drinks made with fresh, pureed fruit) may contain significant amounts of fiber, sorbitol and (poly)phenols, whereas a strained juice or juice from concentrate may contain sorbitol and (poly)phenols, but little fiber (Fig. 1).

Fruit pomace (by-product of juice-extraction that consists of fruit skin, seed or pips and possibly stems) is unlikely to contain significant amounts of sorbitol due to its high solubility and therefore extraction in the juice, although data for the composition of fruit pomace is lacking. In the case of fruit extracts, or seed extracts, the fiber is usually absent, and the (poly)phenol or sorbitol content depends on the extraction procedure. The sorbitol content of fruit peels is under-investigated but some studies measuring the sorbitol of peeled and unpeeled fruits yield values that imply the presence of sorbitol in peels. ${ }^{63}$ Fruit peels and fiber isolates may also contain (poly)phenols, again depending upon the isolation procedure, ${ }^{64,65}$ hence their health effects may be attributed to both fiber and (poly)phenols (Fig. 1).

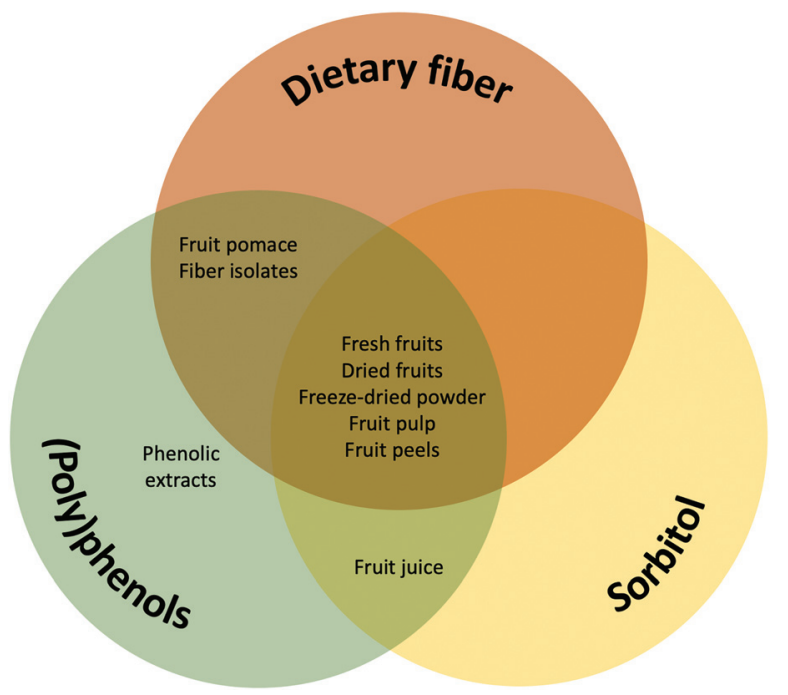

Fig. 1 The major components of fruits likely to impact the gut microbiota, gut motility and constipation and their presence in fruit and fruit products.

Moreover, the complex food matrix of each fruit product may play a role in the bioaccessibility of each compound. (Poly)phenols can be bound to dietary fibers, and after fiber fermentation by the colonic microbiota are released and become available to the local bacterial communities and the host. This can lead to a series of local health effects. ${ }^{66}$

Consequently, different fruit products, even from the same fruit may have varying effects on gut microbiota, gut function and motility due to their varying content of fiber, sorbitol, (poly)phenols, and other, less investigated compounds (e.g. tartaric acid or oxyphenisatin. ${ }^{38,67}$ However, very few studies directly compare the effects of the different fruit components contained within different fruit products. Thus, there is limited evidence on which fruit components play a predominant role in regulating gut motility and constipation, or whether a synergic effect of multiple components is in fact responsible for such effects.

\section{Fruit and fruit products, the microbiota and gut motility}

Several fruits and fruit products have been investigated for their effects on the gut microbiota, gut motility and constipation. The human studies included in this review are summarized in Table 1.

\section{Stone fruits}

Plums (species of the genus Prunus), in the form of dried plums (prunes) or plum juice, are the most widely investigated for their impact on gut motility and constipation, with 7 RCTs and a systematic review published in total about these effects, ${ }^{6-76}$ yet few of them looked into mechanistic outcomes. One RCT in healthy males, reported a higher fecal weight after the consumption of $100 \mathrm{~g} \mathrm{~d}^{-1}$ of prunes for four weeks compared to $360 \mathrm{~mL}$ of grape juice, with no changes in fecal water content. ${ }^{76}$ In an RCT, four weeks of prune consumption (80 g 


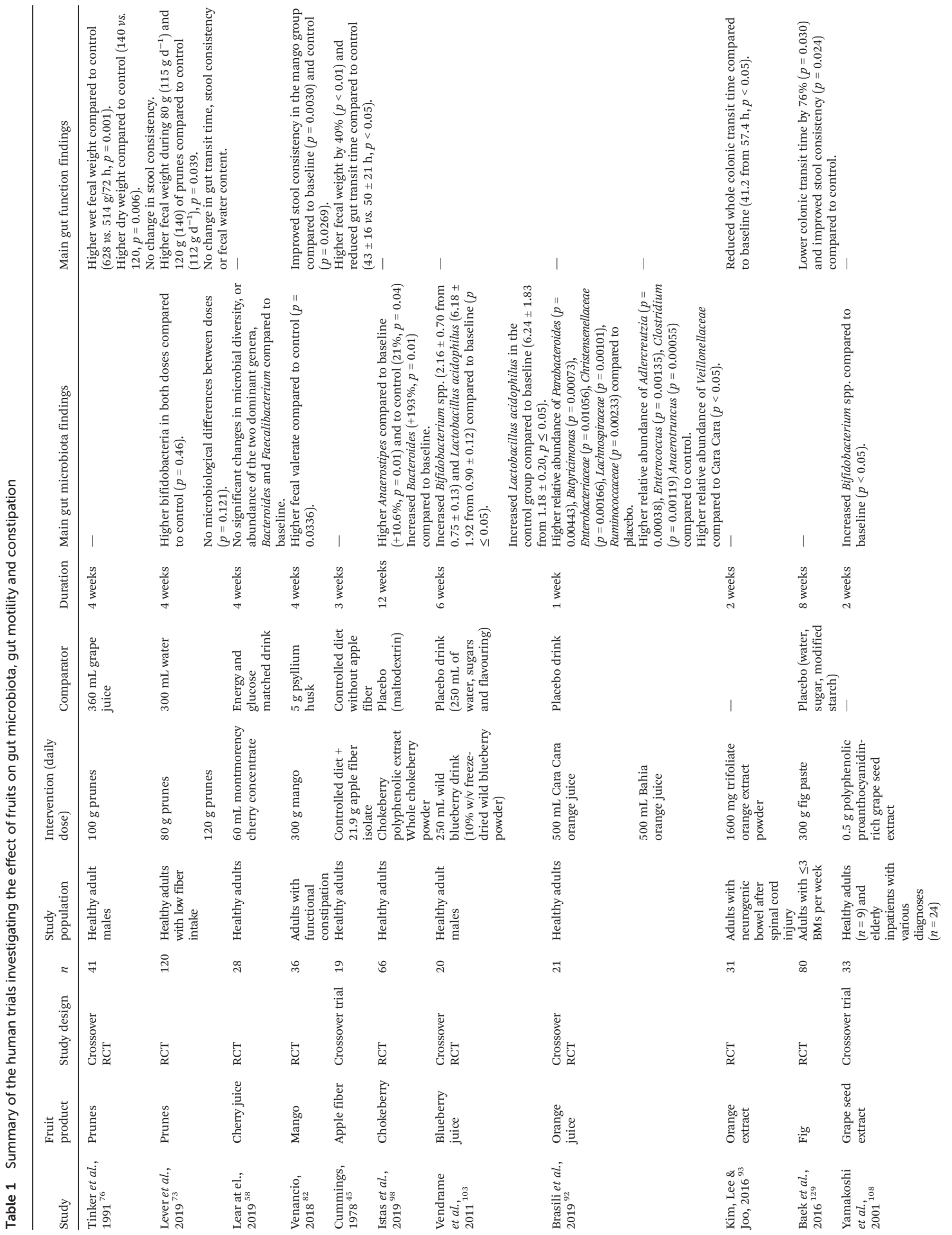



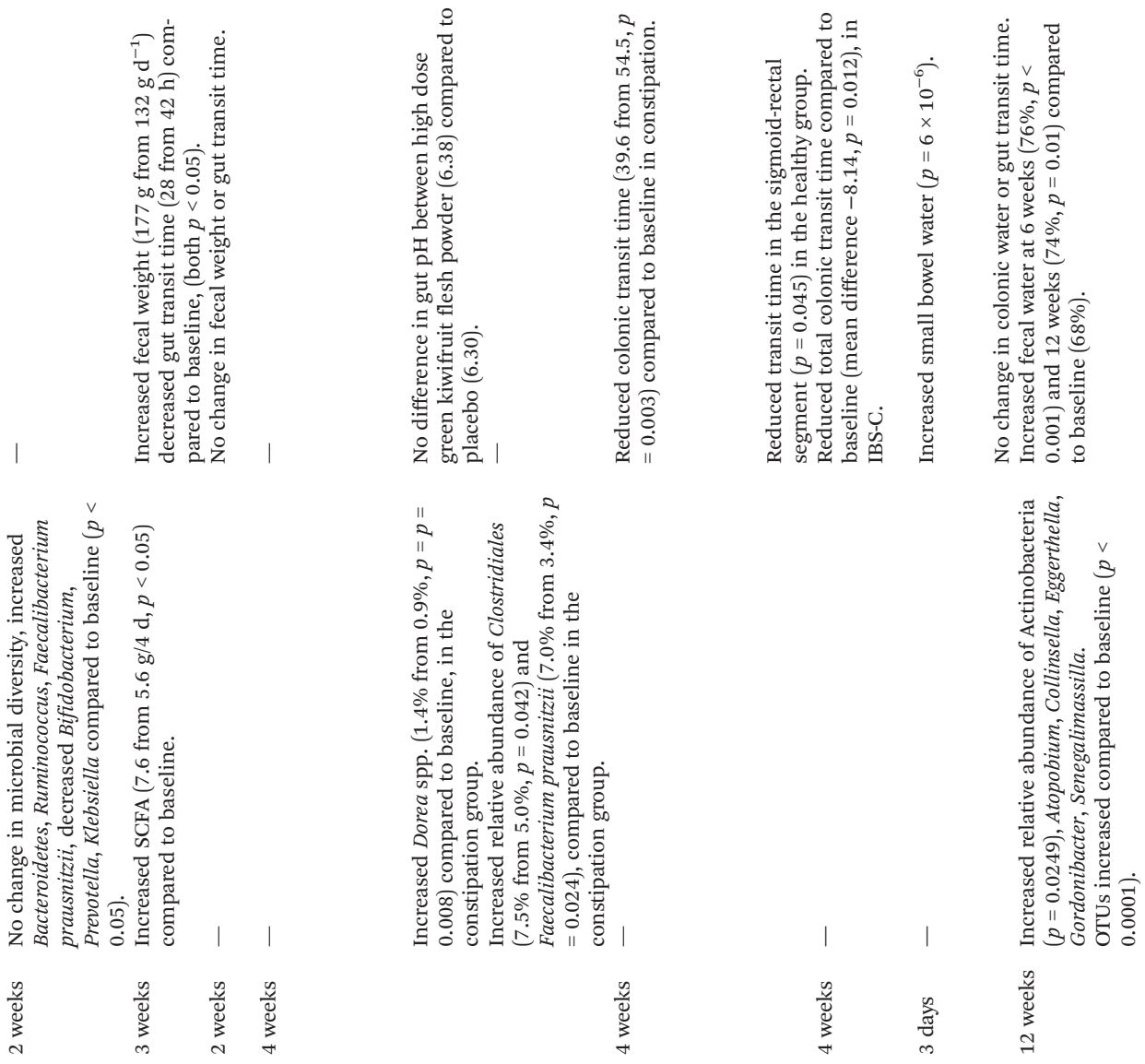

$\frac{n}{\frac{n}{8}}$

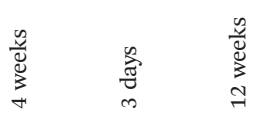
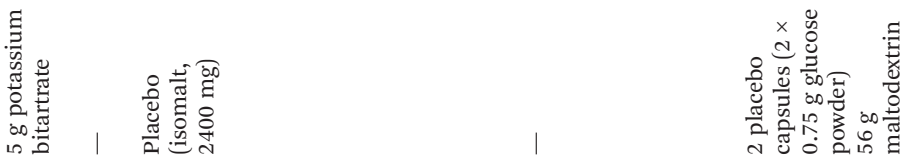

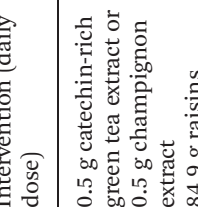
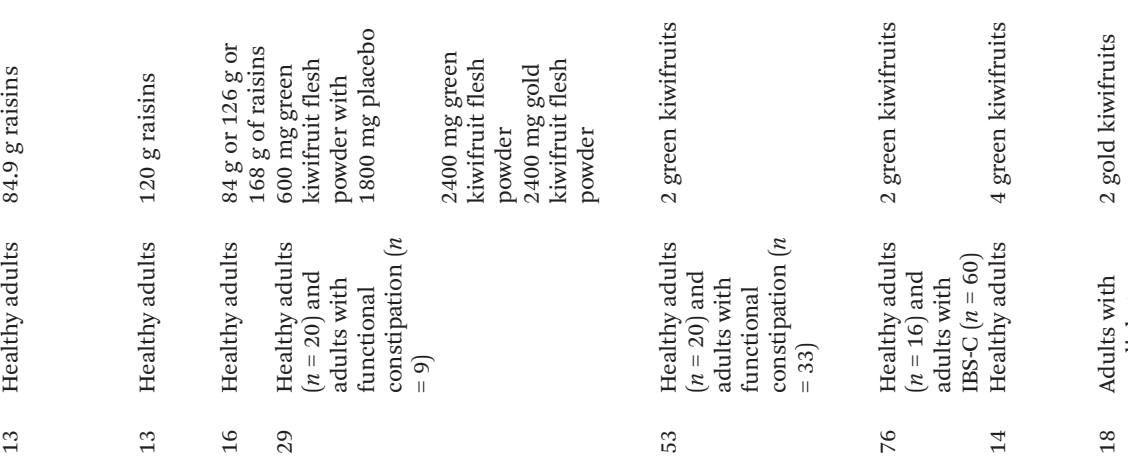

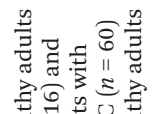

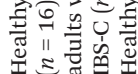

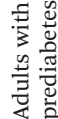

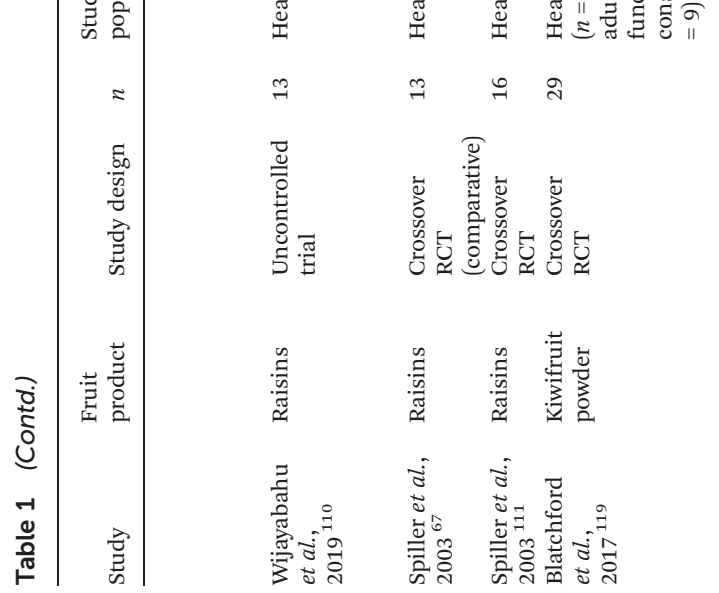

is

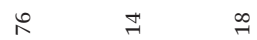

尊

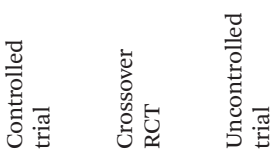

言

ปั่

政

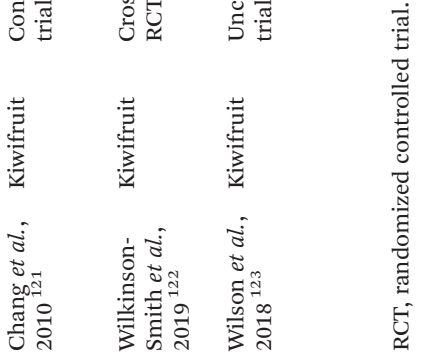


$\mathrm{d}^{-1}$ or $120 \mathrm{~g} \mathrm{~d}^{-1}$ prunes) resulted in greater fecal weight compared to control (no prunes) but did not increase fecal water content or whole gut transit time. The two prune-receiving groups had increased baseline-to-endpoint changes in the abundances of bifidobacteria compared to control, but with no significant difference between the two doses. ${ }^{73}$

Plum juice has been investigated for its effect on the microbiota in a four-arm study on obese rats in which carbohydratefree plum juice was compared to carbohydrate-free peach juice and control (a water-glucose drink), with an extra, negative control group of lean rats who received the control. Plum juice resulted in higher Turicibacter, Faecalibacterium and Lactobacillus abundances compared to all other groups, while Ruminococcaceae were higher compared to the two control groups. $^{77}$

Overall, in humans, prunes increase fecal bulk but not fecal water. The differences in the changes in microbiota that were observed between plum products might be explained by the fiber, which was present in the prunes in the human trials, while not present in the plum juice fed to rats, however, of course, different organisms were studied which itself confounds results. The increases of bifidobacteria observed in the human trial is promising, as lower bifidobacteria have been observed in constipation and it is possible this reduction plays a role in its pathogenesis, but also because bifidobacteria exert gut health benefits. ${ }^{78}$

Apricots, which belong to the same genus as prunes, are also rich in fiber and sorbitol. Only one study reported higher fecal weight, fecal lipid content as well as higher relative abundances of Bacteroides and Clostridium cluster IV in mice fed Japanese apricot (Prunus mume) fiber isolate compared to control (cellulose) ${ }^{79}$ While there is no evidence to support the extrapolation of these results to humans, this study suggests apricots may modulate microbiota composition and further research is needed as to whether this occurs in humans.

Cherries (species of the genus Prunus) have also shown potential to alter the gut microbiota. One animal and one human study have investigated their effects in the gut. In obese mice, the supplementation of whole, dark, sweet cherry powder for 12 weeks lead to higher abundances of Akkermansia, Alcaligenaceae and Bifidobacterium while also resulted in 10-fold lower Lactobacillus and Enterobacteriaceae abundances compared to the two control groups (obese and lean mice receiving a cherry-free diet). ${ }^{80}$ In an RCT in healthy adults, however, despite extensive $16 \mathrm{~S}$ sequencing, a 4-week supplementation of $60 \mathrm{~mL} \mathrm{~d}^{-1}$ of Montmorency cherry concentrate did not have any effects on the gut microbiota compared to control, which was an energy and glucose matched drink. ${ }^{58}$ The difference between these studies could indicate that the effects seen in animals may not be transferrable to humans, or that cherry concentrate lacks the effective components which freeze-dried cherry powder has, or finally, the lack of effect in humans could be a type II error resulting from a small sample size $(n=28)$.

Mangoes, stone fruits of the plant Mangifera indica L., belonging in the Anacardiaceae family. ${ }^{81}$ One RCT in 36 adults with constipation compared a daily consumption of $300 \mathrm{~g}$ of mango to $5 \mathrm{~g}$ of psyllium husk daily for 4 weeks. Mango resulted in greater fecal content of valerate compared to control and improved stool consistency, however fecal water content was not measured. ${ }^{82}$ Psyllium husk and mango have a comparable ratio of soluble to insoluble fibers. ${ }^{83,84}$ As the fiber was matched between the interventions, the differences in these results may occur due to the (poly)phenol content of the mango.

Overall, prunes and apricots increase fecal output in humans and animals, which could be useful in constipation. The disparities between microbial effects of stone fruits may be a result of the differences in the fiber, sorbitol or (poly) phenol content or each fruit (e.g. plums or apricots) or their presentation (fruit or juice), and may also arise indirectly from a potential altered gut motility, which is known to affect the local microbiota. ${ }^{14,30,85}$

\section{Pome fruits}

Apples (species of the genus Malus) have also been studied in three animal studies, one in vitro experiment and one human trial, regarding their effects on gut function. Apple pulp fed to rats for seven days resulted in higher wet and dry fecal weight compared to control. ${ }^{86}$ This effect was also observed in a clinical trial of six healthy adults that compared apple fiber isolate supplementation of a controlled diet to the same diet without fiber addition for three weeks; greater fecal weight and lower gut transit time was reported in the apple fiber isolate compared to control. ${ }^{45}$

Studies have also compared different apple components for their effects on the gut microbiota. A controlled animal study compared the effects of several apple products (apple juice, apple purée, apple pomace and $0.33 \%$ or $3.3 \%$ apple pectin isolate) in rats for 14 weeks. Only butyrate was found to be affected by the interventions, with higher cecal concentrations in the apple pomace and the 3.3\% apple pectin groups compared to control (no apple). Similar findings were reported in a follow-up experiment, comparing the effects of a control diet supplementation with $7 \%$ apple pectin or $10 \mathrm{~g} \mathrm{~d}^{-1}$ whole apple, which resulted in higher butyrate and lower cecal $\mathrm{pH}$ for both interventions compared to control. Furthermore, the 16S rRNA gene content of Bacteroides was lower in pectin-fed and whole apple-fed rats compared to control and when comparing the two apple groups, only Clostridium coccoides was significantly higher in the apple pectin group compared to the whole apple group. ${ }^{87}$ Another controlled study investigated the effects of whole apple, apple peel, apple polyphenolic extract and grape polyphenolic extract in mice. Whole apple resulted in a higher abundance of Akkermansia, whereas apple peel led to greater abundance of Bacteroides compared to control. The apple and grape polyphenolic extracts resulted in higher Enterobacteriaceae, Turicibacter and Enterococcus compared to control. ${ }^{88}$ Overall, these animal studies indicate broadly similar effects of different components of apple (e.g. whole, pomace) compared with apple fiber isolate, suggesting that any effect of apple on microbiota and gut function may be 
driven largely by the fiber component directly, or indirectly by potential changes in gut motility.

Considering different apple cultivars, a recent study investigated the effects of Renetta Canada, Golden Delicious and Pink Lady compared to inulin and cellulose on microbiota using a batch-culture colonic fermentation model. At $24 \mathrm{~h}$ of fermentation, all three apple cultivars increased the relative abundance of Actinobacteria compared to cellulose. Bacteroidetes decreased and Proteobacteria increased over time with Renetta Canada and Golden Delicious, whilst Faecalibacterium prausnitzii increased over time with Renetta Canada. While all apples increased the concentration of total SCFA, acetate and propionate over time, only Renetta Canada increased butyrate. No differences in SCFA were observed between treatments at each time point. ${ }^{89}$ This cultivar comparison showed some significant microbiological differences between the different apple types, possibly explained by the difference in the (poly)phenolic profile of these three cultivars, as the fiber content between them was similar. These are only a small fraction of the existing cultivars though, signifying the need for further investigation of the differences between subspecies, as well as fruit components and fruit products, not only for apples but possibly for other fruits as well.

Overall, regarding immediate gut motility effects, apple products seem to increase fecal output (weight, frequency) in both humans and rats, as well as gut transit time in humans, which may be helpful in constipation.

\section{Citrus fruits}

Orange (Citrus sinensis) is one of the most financially important fruits of the family Rutaceae. ${ }^{90}$ In one simulated human digestion trial using fecal cultures from three donors at risk of metabolic syndrome, orange juice from concentrate was used as a control, to be compared to orange juice supplemented with a galactooligosaccharides mixture. Plain orange juice did not produce any changes to the populations of the bacteria studied in an in vitro colonic model study, nor the SCFA production compared to baseline. ${ }^{91}$ However, some cultivarspecific effects of orange juice were investigated in a randomized crossover trial involving 21 healthy adults, where a daily dose of $500 \mathrm{~mL}$ Cara Cara orange juice was compared to the same portion of Bahia orange juice or a placebo drink. The Cara Cara group had a higher relative abundance of the Porphyromonadaceae family and Parabacteroides genus, and the Odoribacteraceae family and Butyricimonas genus, as well as Enterobacteriaceae, Christensenellaceae, Lachnospiraceae, and Ruminococcaceae families compared to placebo. Bahia orange juice led to a greater relative abundance of the Coriobacteriaceae family and Adlercreutzia genus, the Enterococcaceae family and Enterococcus genus, the Clostridiaceae family and Clostridium genus as well as Ruminococcaceae family and Anaerotruncus genus, compared to control. Between the two cultivars, Bahia led to higher relative abundance of Veillonellaceae compared to Cara Cara, while the latter resulted in higher Eubacterium dolichum than Bahia. Neither variety produced significant changes in the SCFA pro- duction..$^{92}$ Dried trifoliate orange (Poncirus trifoliata (L.) Raf. or Citrus trifoliata L.) was investigated in an RCT on patients with neurogenic bowel after spinal cord injury at a daily dose of $1600 \mathrm{mg}$ of extract powder. It was found to reduce whole colon transit time compared to baseline. ${ }^{93}$ Overall, the existing evidence on two orange varieties show increased Ruminococcaceae concentrations, while the rest of the bacterial families and genera affected differed depending on the varietal. The lack of such an effect in the existing in vitro study may result from the fact that an orange juice from concentrate was used, which would lack fiber and whose (poly)phenol content may have been reduced during the drying process. ${ }^{94}$ Additionally, trifoliate orange extract powder exhibited transit time reducing effects, however, the mechanism of its prokinetic effects is not yet fully understood. The type of extract (aqueous solution, methane or hexane extract) seems to play a significant role in which receptors are affected, in pathways related to the prokinetic activity.

\section{Berries}

Several types of berries have been studied regarding their effect on the gut. Four animal studies on black raspberries, blueberries, blackcurrants, blackberries and raspberries, two human trials on chokeberries and blueberries as well as one in vitro study on cranberries are presented below.

A black raspberry freeze-dried powder supplementation $(10 \% \mathrm{w} / \mathrm{w})$ of a standard feed in mice, led to a higher abundance of Akkermansia municiphila compared to the control group (feed with no supplementation). In the black raspberry group, Firmicutes decreased, while Bacteroidetes increased. ${ }^{95} \mathrm{~A}$ similar change in the ratio of Firmicutes to Bacteroidetes was observed in another study on male mice, comparing a $10 \%$ supplementation of black raspberry freeze-dried powder to a control diet with no supplementation. Specifically, Clostridium was lower while Barnesiella was greater in the colon mucosal samples compared to control. Turicibacter and Lactobacillus were also found to be lower in both medial colon mucosal samples and luminal samples compared to control. $^{96}$ Although information on the sorbitol content of black raspberries is not available, these fruits have a high fiber content $(6.5 \mathrm{~g} \text { per } 100 \mathrm{~g})^{30}$ and high-(poly)phenol content, ${ }^{97}$ which could explain their potency in affecting microbiota as observed in the animal studies available.

Chokeberries (Aronia melanocarpa), have been studied in one RCT in healthy men, where whole chokeberry powder was compared to a polyphenol-rich chokeberry extract and placebo (maltodextrin). The chokeberry extract Anaerostipes was higher compared to baseline and to the control, whereas whole fruit increased Bacteroides compared to baseline. ${ }^{98}$

Cranberries are fruits of several species of the genus Vaccinium. Three products of cranberries were studied in one human gut fermentation simulation study using microbiota of phenotypically healthy donors with increased or absent Enterobacteriaceae. A polyphenol-rich cranberry extract was compared to a polyphenol-free extract, whole cranberry powder and an untreated control fermentation. In the 
Enterobacteriaceae-free community, the phenolic-rich extract increased Bacteroidaceae compared to baseline. In the Enterobacteriaceae-rich community, whole cranberry increased Bacteroidaceae and Porphyromonadaceae, while it decreased Enterobacteriaceae over time. In the same community, the phenolic-deficient extract also increased Porphyromonadaceae compared to baseline. On the contrary, in this community the phenolic-rich extract did not produce any significant changes to the microbiota compared to baseline. ${ }^{99}$ These differences between the effects of different cranberry components possibly indicate that both fiber and polyphenols play a role in the modification of gut bacteria in animal models.

Blueberries also belong in the genus Vaccinium. ${ }^{81}$ Rats fed a high-fat diet with whole blueberry powder supplementation had a greater abundance of Porphyromonadaceae, Gammaproteobacteria, Proteobacteria and Fusobacteria, significantly lower Firmicutes and Bacteroidetes compared to rats fed a high-fat diet and rats fed a low-fat diet, both with no blueberry supplementation. Additionally, the supplementation resulted in higher acetate compared to both non-supplementation groups and higher propionate but lower butyrate than low-fat-fed rats. ${ }^{100}$ An $8 \%$ supplementation of lowbush wild blueberries powder fed to rats for 6 weeks led to higher abundance of Actinobacteria, Coriobacteriaceae and some members of Bifidobacteriaceae, while the abundances of Lactobacillus and Enterococcus were lower compared to rats fed control diets. ${ }^{101}$ In another experiment with freeze-dried blueberry powder on mice, the changes in the gut microbiota were sexually dimorphic, affecting different genera of bacteria in each sex. In male mice, the consumption increased Corynebacterium, Clostridium, and Facklamia and decreased Ruminococcus and RF39 over time, while in female mice it increased Turicibacter, Mogibacteriaceae, Coprococcus, Adlercreutzia, and S24-7 and decreased Ruminococcus, Mucispirillum, Christensenellaceae, Anaerotruncus, and Staphylococcus. ${ }^{102}$ A randomized, repeated-measure, crossover trial on 20 healthy male adults investigated the effects of a daily portion of $250 \mathrm{~mL}$ wild blueberry drink $(10 \% \mathrm{w} / \mathrm{v}$ freezedried wild blueberry powder) compared to a placebo drink. The abundance of Bifidobacterium spp. and Lactobacillus acidophilus increased compared to baseline, although Lactobacillus acidophilus increased in the control group as well. ${ }^{103}$ In summary, wild blueberry powder had positive effects on the human microbiota composition, increasing bifidobacteria and L. acidophilus, despite contrasting effects seen in a previous animal study. ${ }^{101}$ There is a need for caution in the extrapolation of fruit intervention effects seen in animals to humans. The amount of fruit given to the animals is greater than a human could be expected to consume. Furthermore, the one existing human trial $^{103}$ was only performed in men, while sex-related variability in the blueberry effects was observed in the animals, leaving a gap in the knowledge about the effects of this fruit in women, which highlights the need for further human trials with blueberries on a larger, more diverse population.

Freeze-dried blackcurrant (Ribes nigrum) led to greater wet fecal weight in rats compared to freeze-dried blackberry (Rubus subgenus Rubus) and raspberry (Rubus ideaus) (16.1 \pm 1.2 vs. $9.0 \pm 0.3$ vs. $9.3 \pm 0.4 \mathrm{~g} / 5$ days respectively, $p<0.05)$. Dry weight in the blackcurrant group was also higher than that of the raspberry group $(7.2 \pm 0.8 v s .5 .7 \pm 0.2 \mathrm{~g} / 5$ days, $p<0.05)$. The blackcurrant supplementation also resulted in higher total SCFA concentrations than the other berries (152 vs. $150 \mu \mathrm{mol}$, $P=0.002)$, higher cecal acetate (109 vs. $74 \mu \mathrm{mol}, P=0.002)$, propionate (20 vs. $13 \mu \mathrm{mol}, P=0.001)$ and butyrate (17 vs. $13 \mu \mathrm{mol}, P=0.032$ ), while in the proximal and distal colon, the blackcurrant group had higher acetate than the other groups (31 vs. $21 \mu \mathrm{mol}, P<0.001$ ) and the raspberry group had higher butyrate than the rest (4.8 vs. $3.5 \mu \mathrm{mol}, P=0.038$ ). However, this study was not controlled. ${ }^{104}$ While in this animal study freeze-dried black currant seems to be more effective in fecal bulking and SCFA production than two Rubus berries, the lack of a control group deprives us from making assumptions about the effect power of these berries overall.

\section{Grapes}

Grapes (Vitis vinifera) are also berries, rich in fiber, ${ }^{30}$ phenolic compounds ${ }^{105}$ and tartaric acid. ${ }^{67}$ Several grape products have been studied in vitro and in vivo for their gut-related effects. Some examples are presented below.

(Poly)phenolic extracts from white and red grape pomace were studied in an in vitro gastrointestinal digestion model. White grape pomace extract increased the total bacterial count and the abundance of Bifidobacterium spp., while red grape pomace extract increased in all bacterial groups investigated (Actinobacteria, Proteobacteria, Bacteroidetes, Firmicutes, Bifidobacterium and Lactobacillus) apart from Bacteroides, compared to baseline measurements. ${ }^{106}$ Lower cecal $\mathrm{pH}$ and higher cecal SCFA were found in rats fed $71 \mathrm{mg} \mathrm{kg}^{-1}$ proanthocyanidins from grape seeds for 14 weeks, compared to the control group (no supplementation). ${ }^{107}$ A dose of $0.5 \mathrm{~g} \mathrm{~d}^{-1}$ of a polyphenolic, proanthocyanidin-rich extract from grape seeds significantly increased Bifidobacterium spp. in nine healthy adults for 14 days, compared to baseline. ${ }^{108}$

Regarding raisins, an in vitro simulated human digestion model (including simulated digestion and removal of simple sugars) showed lower Bacteroidetes and Firmicutes abundances and higher Actinobacteria and Proteobacteria compared to the control vessel, where no raisins were added. ${ }^{109}$ Additionally, a human trial investigating the effects of three servings of raisins per day for 14 days in 13 healthy adults showed a decrease in Bifidobacterium spp., along with Prevotella spp. and Klebsiella sp., and an increase in Bacteroidetes sp., Ruminococcus sp. and Faecalibacterium prausnitzii compared to baseline. Overall microbial diversity was not altered. ${ }^{110}$ In both studies, the same brand of sun-dried raisins was tested, while the baseline microbial composition in both cases seems to be different. In the in vitro study, fecal slurry from only one donor was used, while the human trial only had 13 subjects. A larger sample size may allow for detection of different effects depending on the subjects' baseline microbiota.

The effect of raisins on human gut transit time or fecal weight has also been studied. In a randomized, crossover, 
comparative trial with 13 healthy adults, $120 \mathrm{~g}$ per day of raisins were compared to an equivalent amount of tartaric acid in the form of $5 \mathrm{~g}$ potassium bitartrate for 3 weeks. Raisins increased fecal weight, decreased intestinal transit time and increased SCFA production compared to baseline. On the contrary, potassium bitartrate did not produce any effects on transit time, fecal weight or SCFA production compared to baseline. The fiber, present only in raisins, may be the reason behind their beneficial effects when comparing it with the potassium bitartrate. ${ }^{67}$ In another randomized, crossover trial, the doses of $84 \mathrm{~g}, 126 \mathrm{~g}$ or $168 \mathrm{~g}$ of raisins for 2 weeks did not produce changes in fecal weight or intestinal transit time in 16 healthy adults, compared to control (a raisin-free, baseline $\operatorname{diet}^{111}$ ). The difference between the results of these two studies may be explained by the shorter duration of the intervention. Evidence also exists on the effects of wine on the gut microbiota; ${ }^{112}$ however, although wine is produced through fermenting grapes, the resulting product's nutrient composition is considerably altered compared to the fruit. Hence, the health effects of wine are not discussed in this review.

While further studies on the multiple products of grape are required to determine their effectiveness in improving gut motility, their nutritional composition seems promising. The current human trials focus on raisins, which may increase fecal weight and decrease transit time, but their effects become significant after 3 weeks of consumption. ${ }^{67,111}$ In one in vitro and one human study, phenolic-rich grape extracts resulted in a bifidogenic effect, however, when raisins were given to humans, bifidobacteria actually decreased. Due to the fiber content of raisins, a bifidogenic effect may be expected. This contradictory finding might be explained by grape seed tannins inhibiting sucrase activity which may result in sucrose and glucose being more available to the colonic microbiota. ${ }^{113}$ While extracts provide these tannins to the host, the seeds in raisins may not be mechanically disrupted in the gastrointestinal tract sufficiently to release the tannins. After raisin consumption in humans, the abundance of Prevotella was lower and Faecalibacterium higher both of which have been observed in constipation. ${ }^{16,17}$ While the observed effects of raisins on human gut function are desirable, those on the gut microbiome are unclear and further studies on the effect of raisins on microbiota are warranted.

\section{Kiwifruit}

Kiwifruits (Actinidia chinensis) are high in fiber and polyphenols ${ }^{114}$ and have been extensively studied for their effect on gut motility and microbiota in two in vitro experiments, two animal studies and five human trials.

Gold and green kiwifruit varieties were studied in an in vitro fermentation model using fecal samples from ten healthy humans. Compared to control (water), both green and gold kiwifruit produced higher Bifidobacterium spp. by 0.8 and $0.9 \log _{10}$ CFU per $\mathrm{mL}$, respectively $(p<0.001)$, BacteroidesPrevotella-Porphyromonas group by 0.5 and $0.4 \log _{10}$ CFU per $\mathrm{mL}$, respectively $(p=0.043)$ and total bacterial numbers $(p=$
0.016) compared to inulin or control. ${ }^{115}$ However, in another simulated gastrointestinal digestion study, green and gold kiwifruit did not alter the abundances of any bacteria when compared to a control fermentation without the addition of kiwifruit. As far as diversity goes, it was also observed that gold kiwifruit resulted in significantly lower species richness than the control vessel. ${ }^{116}$ Different kiwifruit cultivars were also investigated in an animal trial, which compared the effects of a standard diet with supplementation of $10 \%$ dried skin or flesh of kiwiberry (Actinidia arguta 'Hortgem Tahi'), gold kiwifruit (Actinidia chinensis 'Gold3'), green kiwifruit (Actinidia deliciosa 'Hayward') or red kiwifruit (Actinidia chinensis 'Red19'), in rats for 7 days. The same diet with a 10\% wheat bran supplementation was used as a control. Both fruit components of all cultivars were able to increase Lachnospiraceae and Lactobacillus spp. compared to baseline, but so did the control fiber. However, the skin of gold, green and red kiwifruit reduced the abundances of Bifidobacterium spp. compared to baseline, while the control fiber did not. Green kiwifruit skin and flesh, as well as the bran control, significantly increased the total bacteria compared to baseline. A significantly greater dry fecal weight was produced after the skin of gold, green and red kiwifruit, compared to the flesh equivalents. Additionally, the fecal bulking index values (the change of the fecal water-holding ability per $100 \mathrm{~g}$ of dried or fresh fruit component) of the skins of all four cultivars investigated were greater than those of the kiwifruit flesh, both on dry and wet test component basis. This could indicate that the consumption of whole kiwifruit, rather than peeled could have a positive effect on fecal weight and fecal bulking, however, a human study would be needed to verify that the kiwifruit peel has a similar effect on humans. ${ }^{117}$ Peel and flesh of gold kiwifruit (Actinidia chinensis) were also compared to a normal diet in rats. Specifically, $3.80 \mathrm{~g}$ per $\mathrm{kg}$ bw of freeze-dried kiwifruit flesh was compared to $4.60 \mathrm{~g}$ per $\mathrm{kg}$ bw of kiwifruit peels. Flesh and peels, both significantly increased the relative abundance of Lactobacillus (35.15\% and 50.59\% vs. 18.69\%, respectively) and Barnesiella compared to control (14.69\% and $17.24 \%$ vs. $9.83 \%$, respectively, $p<0.05$ for both comparisons). Both kiwifruit flesh and peels also resulted in lower relative abundances of potentially harmful bacteria Enterococcus, Staphylococcus, Escherichia/Shigella and Clostridium XVIII compared to control. ${ }^{118}$

Human trials exploring kiwifruits have also been performed. In a randomized, double-blind, controlled crossover trial, healthy participants and participants with functional constipation received $600 \mathrm{mg} \mathrm{d}^{-1}$ green kiwifruit (Actinidia chinensis var. deliciosa 'Hayward') flesh supplement powder $\left(\right.$ ACTAZIN $^{\mathrm{TM}}$ ) with $1800 \mathrm{mg} \mathrm{d}^{-1}$ placebo (isomalt, $2400 \mathrm{mg}$ $\left.\mathrm{d}^{-1}\right), 2400 \mathrm{mg} \mathrm{d}{ }^{-1}$ ACTAZIN $^{\mathrm{TM}}, 2400 \mathrm{mg} \mathrm{d} \mathrm{d}^{-1}$ gold kiwifruit (Actinidia chinensis var. chinensis 'Zesy002') flesh supplement powder (Livaux ${ }^{\mathrm{TM}}$ ), and finally, a placebo for 28 days each, with a 14-day washout period between interventions. The Livaux ${ }^{\mathrm{TM}}$ treatment significantly increased the relative abundance of Clostridiales, and Faecalibacterium prausnitzii in constipation, compared to baseline. The high dose of ACTAZIN ${ }^{\mathrm{TM}}$ increased 
Dorea spp. in the constipation group compared to baseline. Additionally, those receiving $2400 \mathrm{mg} \mathrm{d}^{-1}$ ACTAZIN $^{\mathrm{TM}}$ and the placebo group were tested with SmartPill ${ }^{\circledR}$, an ingestible medical device that measures intestinal $\mathrm{pH}$. The $\mathrm{pH}$ values were similar between the two groups. ${ }^{119}$ Some human studies have provided additional insight as to the effects of whole, fresh kiwifruit on health. In a clinical trial on constipated and healthy adults, two kiwifruits (Actinidia callosa) per day for four weeks significantly lowered total colonic transit time compared to baseline in the constipated group but not the healthy group, for which a difference in transit time was only observed on the sigmoid-rectal segment. ${ }^{120}$ Bowel movement frequency was also increased, and stool transit time was decreased in patients with IBS-C. ${ }^{121}$ In a healthy-human, crossover RCT the group receiving four kiwifruits per day for three days showed higher small bowel water content compared to control (56 g $\mathrm{d}^{-1}$ of maltodextrin), although the colonic water content and whole gut transit time were not significantly different between the two interventions. These findings translated clinically to softer reported stools compared to the control intervention, although the fecal water content was not measured, and the researchers hypothesize that a greater stool volume is implied. ${ }^{122}$ In a pilot intervention trial, participants were asked to consume the flesh of two Zespri SunGold kiwifruits (Gold3, Actinidia chinensis) per day (approximately $2 \times 95 \mathrm{~g}$ $\mathrm{d}^{-1}$ ), for 12 weeks. This dose increased the fecal water content at weeks 6 and 12 compared to baseline. The relative abundance of Actinobacteria was increased in the kiwifruit intervention compared to baseline. ${ }^{123}$

Once again, the microbiological effects differ between in vitro and animal studies compared to human studies, which could be explained by the different study design and organism but also that in vitro and animal studies can supplement with large amounts of kiwifruits, which would not be feasible in a human diet intervention. Regardless of the type of cultivar (green or gold), kiwifruits seem to favor bacteria such as Lactobacillus spp. and Bifidobacterium spp. in animals, with peels being more effective. The consumption of only the kiwifruit flesh by humans may deprive them of beneficial effects on the microbiota, yet there is no confirmation of this from human trials where either kiwifruit flesh powder or whole kiwifruits were investigated, and it is unclear whether participants peeled the fruits during the study. However, in one human trial, the flesh powder of gold kiwifruit did increase Faecalibacterium prausnitzii. In animals, fecal weight was increased by both flesh and skin of green, gold and red kiwifruit, as well as kiwiberries, which all had a high fecal bulking index. Unfortunately, to our knowledge, this outcome has not been studied in humans. Nevertheless, kiwifruit seems to be able to increase the water retention in the human small intestine and fecal water content, although there are still few studies that explore these outcomes. Additionally, gut transit time was reduced in individuals with constipation but not those with healthy bowel function, possibly because of a difference in the physiology or microbiota between those two groups.

\section{Cactus fruits}

Prickly pear juice (Opuntia ficus-indica L.) has been investigated for its impact on gut motility in two animal studies. Supplementation of 10 or $20 \mathrm{~mL} \mathrm{~kg}{ }^{-1}$ of prickly pear juice to mice led to dose-dependently higher gastrointestinal transit time, while an aqueous solution of prickly pear seeds had the opposite, dose-dependent effect, at the doses of 200 and $400 \mathrm{mg} \mathrm{kg}^{-1}$, compared to control $(\mathrm{NaCl})$. In the same study, compared to control, the dry and wet weight, as well as the fecal water content of the mice given prickly pear juice, were also lower at the doses of $5,10 \mathrm{ml} \mathrm{kg}^{-1}$, while for the dose of $20 \mathrm{ml} \mathrm{kg}^{-1}$, only wet weight and fecal water content were lower. On the contrary, the aqueous seed extract group had significantly higher fecal weight at all doses. The differences in the effects of these two products of the same fruit are attributed to the differences between the composition of the juice and the seeds, with seeds having more fiber, total polyphenols, less sugars and a different mineral profile than that of juice. ${ }^{124}$ In a follow-up study in rats, immature and mature prickly-pear juice were investigated. Mature juice, at the doses of 5, 10 and $20 \mathrm{ml} \mathrm{kg}^{-1}$, resulted in significantly and dose-dependently higher gastrointestinal transit time and lower fecal wet and dry weight compared to control (apart from the dry weight of the highest dose). On the contrary, the same doses of immature juice led to significantly, dose-dependently lower gastrointestinal transit time compared to control. Differences in the effects of the juices at these two maturity stages are attributed to the variation of their chemical composition, as the fiber and sugar content increased with maturity, while total polyphenols were lower in more mature fruits than immature ones (no statistical comparison provided). ${ }^{125}$ As shown from these animal studies, prickly pear seed extract and immature prickly pear juice can result in lower gut transit time in animals, compared to control, while the former has also shown to increase fecal weight, which would be beneficial effects if they are confirmed in human trials. Considering the maturity level changes the chemical composition of most fruits, much like the prickly pear, the nutrient composition or maturity stage should be taken into account for further fruit intervention studies and noted in publications.

White flesh dragon fruit (Hylocereus undatus (Haw) Britt. and Rose) oligosaccharide extract was also studied in one controlled trial on mice, in which the fecal weight after daily doses of 500 and $1000 \mathrm{mg} \mathrm{kg}^{-1}$ for one week was higher by 2.3 times and after the dose of $500 \mathrm{mg} \mathrm{kg}^{-1}$ for two weeks by 2 times, compared to control. The doses of $1000 \mathrm{mg} \mathrm{kg}^{-1}$ for a week and $500 \mathrm{mg} \mathrm{kg}^{-1}$ for two weeks led to lower gut transit time by approximately $30 \%$ compared to control. This effect on transit time was attributed to greater speed and total number of intestinal contractions compared to control after a week of $1000 \mathrm{mg} \mathrm{kg}^{-1} \mathrm{~d}^{-1}$ of dragon fruit. ${ }^{126}$ These results in animals show great potential for fecal bulking and transit time reduction. While red dragon fruit has not yet been studied, it is a better source of fiber and phytochemicals compared to white dragon fruit, ${ }^{127}$ which could suggest that it could be an 
even better candidate to study for gut motility effects and may be worth studying.

\section{Figs}

Figs (Ficus carica) were investigated in one animal and one human study. Increased fecal weight and fecal water content in rats with loperamide-induced constipation fed a dose of 1,6 or $30 \mathrm{~g} \mathrm{~kg}^{-1}$. While before the induced constipation fig supplementation resulted in higher fecal weight and fecal water content compared to control (no supplementation) only in the $30 \mathrm{~g} \mathrm{~kg}^{-1}$ group, after constipation was induced, all three fig groups led to higher fecal weight and water. ${ }^{128}$ An eight-week, randomized, double-blind, placebo-controlled clinical trial in adults with $\leq 3$ bowel movements per week compared a daily dose of $300 \mathrm{~g}$ of fig paste to placebo (water sugar and modified starch). Colonic transit time decreased compared to baseline following both fig paste $(76 \%)$ and placebo $(67 \%)$, with the decrease in the fig paste being significantly greater than that of the placebo. While evidently a placebo effect resulted in a desirable effect in the control group, the statistically significant difference compared with placebo indicate that the nutritional characteristics of the fig paste (high in fiber and phenolics) led to an effect that cannot simply be attributed to a placebo effect, although the additional effect size was relatively small. ${ }^{129}$ Confirmatory studies should be performed to investigate the effect of fig above that of placebo. However, food interventions are hard to mask, the few studies such as the latter that are able to efficiently blind participants by creating an effective placebo indicate the great need for well-controlled nutritional clinical trials.

\section{Summary and discussion of evidence for fruits in humans}

Several fruit products impact the gut microbiota, gut function and may impact constipation. A dietary intervention for constipation would seek to reduce gut transit time and increase fecal weight, both of which could potentially decrease the risk of other gastrointestinal disorders. Additionally, an increase in fecal water could lead to softer stools and easier passage, a beneficial outcome in constipation.

Review of the current literature on fruits has found evidence that prunes, apple fiber isolate and raisins increased fecal weight in humans (Table 1). Kiwifruit is the only fruit proven to increase fecal and small bowel water content in humans, however, this review focused on mechanistic evidence rather than clinical evidence, therefore trials presenting data on selfreported stool consistency were not included. Apple fiber isolate, kiwifruit, fig paste, and trifoliate orange extract powder reduced gut transit time, while prunes did not, despite their proven bulking effect (Table 1). However, in the case of kiwifruit, its ability to reduce gut transit time was observed only in a group of constipated patients but not in healthy individuals of the same study.
Altered microbiota have been associated with constipation in several studies. Patients with constipation have been shown to have lower Bacteroidetes (Bacteroides and Prevotella) bifidobacteria, lactobacilli and Roseburia compared to healthy individuals. ${ }^{14-17}$ Studies have also reported higher abundance of genera from the Firmicutes phylum, such as Faecalibacterium in constipation. ${ }^{15,16}$ The modulation of these bacteria may be helpful in the management of constipation and some fruits may be able to achieve that. At genus level, only one human study showed fruits increased lactobacilli, specifically by a wild blueberry powder drink, while others did not show similar results. However, several other fruits having such effects in in vitro and animal studies. Bifidobacteria, which are associated with beneficial health effects, including an association with faster transit time, ${ }^{130}$ were increased by a wild blueberry powder drink, prunes, and a polyphenolic extract of grape seeds, in contrast to raisins which decreased the abundance of this genus. Bacteroides, whose lower abundance in constipation may be secondary to alterations of the intestinal motility and the metabolic environment of the gut, ${ }^{15}$ was only increased by chokeberry powder in one human trial. ${ }^{98}$ Higher abundances of Ruminococcaceae have also been found in constipation, ${ }^{15}$ but their abundance was only increased by the consumption of raisins (Table 1). At species level, Faecalibacterium prausnitzii, was increased in humans by a green kiwifruit flesh powder supplement and raisins. While lower abundances of $F$. prausnitzii have been reported in IBS-C, and it is abundant in the healthy human gut microbiome, ${ }^{131}$ at the genus level constipation has been associated with higher Faecalibacterium abundances, ${ }^{15,16}$ Paradoxically, Faecalibacterium is a butyrate-producing genus, which may stimulate gut transit through the production of serotonin, but at higher concentrations may inhibit gut transit and induce constipation. ${ }^{17,132-134}$

It has been suggested that a pharmacological treatment regulating bowel movement frequency may temporarily modify the gut microbiota in constipation, indicating that slow transit may affect gut microbiological communities. ${ }^{14}$ As seen in this review, fruits also have the potential to affect gut motility, therefore indirectly create a short-term alteration in gut microbiota. Future study design, including a positive control with stimulant laxatives (e.g. Prucalopride), as well as a follow-up measurement after the fruit intervention has ended could determine if the effects of fruits in the gut microbiome are direct or indirect, short-lived or permanent.

Apart from the effect of motility on gut microbiota, it has also been hypothesized that the metabolites produced may further slow transit. ${ }^{14} \mathrm{~A}$ long-term diet that integrates fruits with proven positive effects on desirable bacteria, could potentially contribute to stopping this vicious cycle. Extensive research will have to be performed to confirm whether fruits are able to have a large-scale, lasting effect on the microbiome, gut motility and constipation.

While these findings are very important, they are but a start in the exploration of the potential of fruit interventions in altering gut function. The small number and power of these 
studies, as well as the apparent differences between the composition and efficacy of different fruit products or components, makes it difficult to extract firm conclusions for each fruit, fruit component or fruit cultivar. However, based on the knowledge behind the fruits' composition of fiber (and type of fiber), sorbitol and (poly)phenols, which have been shown to improve gut motility, as well as the animal studies suggesting some potential effects may also be applicable to humans, this field of research is promising.

The fact that the studies that compare different fruit products, cultivars or ripeness stages show dissimilar and sometimes even opposite effects deems it appropriate that the cultivar and stage of ripeness are considered as variables, and are described in future publications. These indications highlight the need for further studies on nutrient and phytochemical analysis of fruits and parts of fruits.

\section{Conclusions}

Current constipation treatment approach includes dietary modifications including fiber- and sorbitol-rich fruits. Based on the literature cited in this review, fruits may have an impact on gut motility as evidence shows that they can affect several aspects of gut physiology and microbiota. Nonetheless, different cultivars, parts or forms of a fruit may exert different effects on the human gut. While fruits are perceived as helpful in constipation symptom alleviation by the public and are widely suggested as a measure to improve constipation symptoms by healthcare professionals, little is yet known about fruits' effectiveness and the mechanisms behind any potential effects.

\section{Author contributions}

All authors were involved in the conception, development and writing of the review; all authors have read and approved the final manuscript.

\section{Conflicts of interest}

ZK is supported by a doctoral fellowship from the International Nut and Dried Fruit Council. ED has received an education grant from Alpro, research funding from the British Dietetic Association, Almond Board of California, the International Nut and Dried Fruit Council and Nestec Ltd and has served as a consultant for Puratos. ARM has received research funding from the Wild Blueberry Association of North America, The National Processed Raspberry Council, The Cranberry Institute, Naturex Inc. and Mars Ltd. KW has received research funding from the Almond Board of California, Clasado Biosciences, Danone, the International Nut and Dried Fruit Council, Nestec Ltd. He is the coinventor of a mobile app to support patients following the low FODMAP diet.

\section{Acknowledgements}

This review was part of a Ph.D. studentship funded by the International Nut and Dried Fruit Council. The funders played no role in the design, interpretation of data, writing of the review, or the decision to submit the paper for publication.

\section{References}

1 F. Mearin, B. E. Lacy, L. Chang, W. D. Chey, A. J. Lembo, M. Simren and R. Spiller, Bowel Disorders, Gastroenterology, 2016, 150(6), 1393-1407.

2 M. Camilleri, A. C. Ford, G. M. Mawe, P. G. Dinning, S. S. Rao, W. D. Chey, M. Simrén, A. Lembo, T. M. YoungFadok and L. Chang, Chronic constipation, Nat. Rev. Dis. Primers, 2017, 3, 17095.

3 D. A. Drossman, Functional Gastrointestinal Disorders: History, Pathophysiology, Clinical Features and Rome IV, Gastroenterology, 2016, 150(6), 1262-1279.

4 S. S. Rao, Constipation: evaluation and treatment of colonic and anorectal motility disorders, Gastrointest. Endosc. Clin. N. Am., 2009, 19, 117-139, vii.

5 C. J. Black and A. C. Ford, Chronic idiopathic constipation in adults: epidemiology, pathophysiology, diagnosis and clinical management, Med. J. Aust., 2018, 209, 86-91.

6 N. C. Suares and A. C. Ford, Prevalence of, and risk factors for, chronic idiopathic constipation in the community: systematic review and meta-analysis, Am. J. Gastroenterol., 2011, 106, 1582-1591; quiz 1581, 1592.

7 A. C. Shafe, S. Lee, J. S. Dalrymple and P. J. Whorwell, The LUCK study: Laxative Usage in patients with GP-diagnosed Constipation in the UK, within the general population and in pregnancy. An epidemiological study using the General Practice Research Database (GPRD), Ther. Adv. Gastroenterol., 2011, 4, 343-363.

8 J. Tack, S. Müller-Lissner, V. Stanghellini, G. Boeckxstaens, M. A. Kamm, M. Simren, J. P. Galmiche and M. Fried, Diagnosis and treatment of chronic constipation-a European perspective, Neurogastroenterol. Motil., 2011, 23, 697-710.

9 A. Albu, A. Farcas, L. David and D. L. Dumitrascu, The economic burden of constipation therapy, Med. Pharm. Rep., 2019, 92, 261-264.

10 Q. Cai, J. L. Buono, W. M. Spalding, P. Sarocco, H. Tan, J. J. Stephenson, R. T. Carson and J. A. Doshi, Healthcare costs among patients with chronic constipation: a retrospective claims analysis in a commercially insured population, J. Med. Econ., 2014, 17, 148-158.

11 Bowel Interest Group, Cost of Constipation Report, https:// bowelinterestgroup.co.uk/resources/cost-of-constipationreport-2020/, (accessed 5 September, 2020).

12 B. C. Martin, V. Barghout and A. Cerulli, Direct medical costs of constipation in the United States, Manag. Care Interface, 2006, 19, 43-49. 
13 W. G. Organization, Constipation: a global perspective, World Gastroenterology Organization Global Guidelines, 2010.

14 I. L. Khalif, E. M. Quigley, E. A. Konovitch and I. D. Maximova, Alterations in the colonic flora and intestinal permeability and evidence of immune activation in chronic constipation, Dig. Liver Dis., 2005, 37, 838-849.

15 L. Mancabelli, C. Milani, G. A. Lugli, F. Turroni, M. Mangifesta, A. Viappiani, A. Ticinesi, A. Nouvenne, T. Meschi, D. van Sinderen and M. Ventura, Unveiling the gut microbiota composition and functionality associated with constipation through metagenomic analyses, Sci. Rep., 2017, 7, 9879.

16 G. Parthasarathy, J. Chen, X. Chen, N. Chia, H. M. O'Connor, P. G. Wolf, H. R. Gaskins and A. E. Bharucha, Relationship Between Microbiota of the Colonic Mucosa vs Feces and Symptoms, Colonic Transit, and Methane Production in Female Patients With Chronic Constipation, Gastroenterology, 2016, 150(2), 367-379.

17 L. Zhu, W. Liu, R. Alkhouri, R. D. Baker, J. E. Bard, E. M. Quigley and S. S. Baker, Structural changes in the gut microbiome of constipated patients, Physiol. Genomics, 2014, 46, 679-686.

18 S. S. Rao, K. Rattanakovit and T. Patcharatrakul, Diagnosis and management of chronic constipation in adults, Nat. Rev. Gastroenterol. Hepatol., 2016, 13, 295-305.

19 B. W. Aichbichler, H. H. Wenzl, C. A. S. Ana, J. L. Porter, L. R. Schiller and J. S. Fordtran, A Comparison of Stool Characteristics from Normal and Constipated People, Dig. Dis. Sci., 1998, 43, 2353-2362.

20 J. H. Cummings, S. A. Bingham, K. W. Heaton and M. A. Eastwood, Fecal weight, colon cancer risk, and dietary intake of nonstarch polysaccharides (dietary fiber), Gastroenterology, 1992, 103, 1783-1789.

21 J. Citronberg, E. D. Kantor, J. D. Potter and E. White, A prospective study of the effect of bowel movement frequency, constipation, and laxative use on colorectal cancer risk, Am. J. Gastroenterol., 2014, 109, 16401649.

22 A. Wald, C. Scarpignato, S. Mueller-Lissner, M. A. Kamm, U. Hinkel, I. Helfrich, C. Schuijt and K. G. Mandel, A multinational survey of prevalence and patterns of laxative use among adults with self-defined constipation, Aliment. Pharmacol. Ther., 2008, 28, 917-930.

23 X. Zhang, K. Wu, E. Cho, J. Ma, A. T. Chan, X. Gao, W. C. Willett, C. S. Fuchs and E. L. Giovannucci, Prospective cohort studies of bowel movement frequency and laxative use and colorectal cancer incidence in US women and men, Cancer, Causes Control, 2013, 24, 1015-1024.

24 A. Guérin, R. Mody, B. Fok, K. L. Lasch, Z. Zhou, E. Q. Wu, W. Zhou and N. J. Talley, Risk of developing colorectal cancer and benign colorectal neoplasm in patients with chronic constipation, Aliment. Pharmacol. Ther., 2014, 40, 83-92.

25 J. F. Johanson, Review of the treatment options for chronic constipation, MedGenMed, 2007, 9, 25.
26 G. Lindberg, S. S. Hamid, P. Malfertheiner, O. O. Thomsen, L. B. Fernandez, J. Garisch, A. Thomson, K. L. Goh, R. Tandon, S. Fedail, B. C. Wong, A. G. Khan, J. H. Krabshuis and A. LeMair, World Gastroenterology Organisation global guideline: Constipation-a global perspective, J. Clin. Gastroenterol., 2011, 45, 483-487.

27 National Institute for Health and Care Excellence, Scenario: Constipation in adults, https://cks.nice.org.uk/ constipation\#!scenario, (accessed 11 May, 2020).

28 National Health Service, Constipation, https://www.nhs. uk/conditions/constipation/, (accessed 11 May, 2020).

29 S. A. Müller-Lissner, V. Kaatz, W. Brandt, J. Keller and P. Layer, The perceived effect of various foods and beverages on stool consistency, Eur. J. Gastroenterol. Hepatol., 2005, 17, 109-112.

30 U.S. Department of Agriculture, FoodData Central, fdc. nal.usda.gov, (accessed 25 March 2021).

31 E. Widdowson and R. A. McCance, McCance and Widdowson's the composition of foods, Institute of Food Research, Public Health England \& Royal Society of Chemistry Great Britain, 7th edn, 2015.

32 J. L. Slavin and B. Lloyd, Health benefits of fruits and vegetables, Adv. Nutr., 2012, 3, 506-516.

33 World Health Organisation, Diet, nutrition and the prevention of chronic diseases, W. H. O. Tech. Rep. Ser., 2003, 916, i-viii, 1-149, backcover.

34 S. Christodoulides, E. Dimidi, K. C. Fragkos, A. D. Farmer, K. Whelan and S. M. Scott, Systematic review with metaanalysis: effect of fibre supplementation on chronic idiopathic constipation in adults, Aliment. Pharmacol. Ther., 2016, 44, 103-116.

35 K. Makki, E. C. Deehan, J. Walter and F. Bäckhed, The Impact of Dietary Fiber on Gut Microbiota in Host Health and Disease, Cell Host Microbe, 2018, 23, 705-715.

36 N. C. Suares and A. C. Ford, Systematic review: the effects of fibre in the management of chronic idiopathic constipation, Aliment. Pharmacol. Ther., 2011, 33, 895-901.

37 J. Yang, H. P. Wang, L. Zhou and C. F. Xu, Effect of dietary fiber on constipation: a meta analysis, World J. Gastroenterol., 2012, 18, 7378-7383.

38 J. Ritchie, Mass peristalsis in the human colon after contact with oxyphenisatin, Gut, 1972, 13, 211-219.

39 J. McRorie, N. Zorich, K. Riccardi, L. Bishop, T. Filloon, S. Wason and R. Giannella, Effects of olestra and sorbitol consumption on objective measures of diarrhea: impact of stool viscosity on common gastrointestinal symptoms, Regul. Toxicol. Pharmacol., 2000, 31, 59-67.

40 Scientific Advisory Committee on Nutrition, Carbohydrates and Health, TSO, London, 2015.

41 S. K. Gill, M. Rossi, B. Bajka and K. Whelan, Dietary fibre in gastrointestinal health and disease, Nat. Rev. Gastroenterol. Hepatol., 2021, 18, 101-116.

42 M. F. Chaplin, Fibre and water binding, Proc. Nutr. Soc., 2003, 62, 223-227.

43 I. A. Brownlee, The physiological roles of dietary fibre, Food Hydrocolloids, 2011, 25, 238-250. 
44 S. Eswaran, J. Muir and W. D. Chey, Fiber and functional gastrointestinal disorders, Am. J. Gastroenterol., 2013, 108, 718-727.

45 J. H. Cummings, W. Branch, D. J. Jenkins, D. A. Southgate, H. Houston and W. P. James, Colonic response to dietary fibre from carrot, cabbage, apple, bran, Lancet, 1978, 1, 5-9.

46 J. H. Cummings, M. J. Hill, D. J. Jenkins, J. R. Pearson and H. S. Wiggins, Changes in fecal composition and colonic function due to cereal fiber, Am. J. Clin. Nutr., 1976, 29, 1468-1473.

47 J. R. Lupton, J. L. Morin and M. C. Robinson, Barley bran flour accelerates gastrointestinal transit time, J. Am. Diet. Assoc., 1993, 93, 881-885.

48 S. A. Müller-Lissner, Effect of wheat bran on weight of stool and gastrointestinal transit time: a meta analysis, $\mathrm{Br}$. Med.J. (Clin. Res. Ed.), 1988, 296, 615-617.

49 A. N. Wick, M. C. Almen and L. Joseph, The metabolism of sorbitol, J. Am. Pharm. Assoc., 1951, 40, 542-544.

$50 \mathrm{Y}$. Lu, Humectancies of d-tagatose and d-sorbitol, Int. J. Cosmet. Sci., 2001, 23, 175-181.

51 P. Born, C. Bauch, K. Ulm, K. Kamereck, M. Classen and W. Scheppach, Fecal bacterial activity in symptomatic carbohydrate malabsorption: effect on the fecal shortchain fatty acid ratio, Z. Gastroenterol., 2000, 38, 623626.

52 L. A. Sarmiento-Rubiano, M. Zúñiga, G. Pérez-Martínez and M. J. Yebra, Dietary supplementation with sorbitol results in selective enrichment of lactobacilli in rat intestine, Res. Microbiol., 2007, 158, 694-701.

53 H. M. Merken and G. R. Beecher, Measurement of food flavonoids by high-performance liquid chromatography: A review, J. Agric. Food Chem., 2000, 48, 577-599.

54 R. Puupponen-Pimiä, A. M. Aura, K. M. OksmanCaldentey, P. Myllärinen, M. Saarela, T. Mattila-Sandholm and K. Poutanen, Development of functional ingredients for gut health, Trends Food Sci. Technol., 2002, 13, 3-11.

55 M. N. Clifford, Diet-derived phenols in plasma and tissues and their implications for health, Planta Med., 2004, 70, 1103-1114.

56 F. Cardona, C. Andrés-Lacueva, S. Tulipani, F. J. Tinahones and M. I. Queipo-Ortuño, Benefits of polyphenols on gut microbiota and implications in human health, J. Nutr. Biochem., 2013, 24, 1415-1422.

57 P. Dolara, C. Luceri, C. De Filippo, A. P. Femia, L. Giovannelli, G. Caderni, C. Cecchini, S. Silvi, C. Orpianesi and A. Cresci, Red wine polyphenols influence carcinogenesis, intestinal microflora, oxidative damage and gene expression profiles of colonic mucosa in F344 rats, Mutat. Res., 2005, 591, 237-246.

58 R. Lear, M. O'Leary, L. O’Brien Andersen, C. C. Holt, C. R. Stensvold, M. van der Giezen and J. L. Bowtell, Tart Cherry Concentrate Does Not Alter the Gut Microbiome, Glycaemic Control or Systemic Inflammation in a Middle-Aged Population, Nutrients, 2019, 11(5), 1063.
59 M. I. Queipo-Ortuño, M. Boto-Ordóñez, M. Murri, J. M. Gomez-Zumaquero, M. Clemente-Postigo, R. Estruch, F. Cardona Diaz, C. Andrés-Lacueva and F. J. Tinahones, Influence of red wine polyphenols and ethanol on the gut microbiota ecology and biochemical biomarkers, Am. J. Clin. Nutr., 2012, 95, 1323-1334.

60 N. M. Roudsari, N. A. Lashgari, S. Momtaz, M. H. Farzaei, A. M. Marques and A. H. Abdolghaffari, Natural polyphenols for the prevention of irritable bowel syndrome: molecular mechanisms and targets; a comprehensive review, Daru, 2019, 27, 755-780.

61 X. Tzounis, A. Rodriguez-Mateos, J. Vulevic, G. R. Gibson, C. Kwik-Uribe and J. P. Spencer, Prebiotic evaluation of cocoa-derived flavanols in healthy humans by using a randomized, controlled, double-blind, crossover intervention study, Am. J. Clin. Nutr., 2011, 93, 62-72.

62 X. Tzounis, J. Vulevic, G. G. Kuhnle, T. George, J. Leonczak, G. R. Gibson, C. Kwik-Uribe and J. P. Spencer, Flavanol monomer-induced changes to the human faecal microflora, Br. J. Nutr., 2008, 99, 782-792.

63 J. G. Muir, R. Rose, O. Rosella, K. Liels, J. S. Barrett, S. J. Shepherd and P. R. Gibson, Measurement of shortchain carbohydrates in common Australian vegetables and fruits by high-performance liquid chromatography (HPLC), J. Agric. Food Chem., 2009, 57, 554-565.

64 J. Pérez-Jiménez and F. Saura-Calixto, Fruit peels as sources of non-extractable polyphenols or macromolecular antioxidants: Analysis and nutritional implications, Food Res. Int., 2018, 111, 148-152.

65 F. Saura-Calixto, J. Pérez-Jiménez, S. Touriño, J. Serrano, E. Fuguet, J. L. Torres and I. Goñi, Proanthocyanidin metabolites associated with dietary fibre from in vitro colonic fermentation and proanthocyanidin metabolites in human plasma, Mol. Nutr. Food Res., 2010, 54, 939-946.

66 L. Jakobek and P. Matić, Non-covalent dietary fiber Polyphenol interactions and their influence on polyphenol bioaccessibility, Trends Food Sci. Technol., 2019, 83, 235-247.

67 G. A. Spiller, J. A. Story, E. J. Furumoto, J. C. Chezem and M. Spiller, Effect of tartaric acid and dietary fibre from sun-dried raisins on colonic function and on bile acid and volatile fatty acid excretion in healthy adults, Br. J. Nutr., 2003, 90, 803-807.

68 A. Attaluri, R. Donahoe, J. Valestin, K. Brown and S. S. Rao, Randomised clinical trial: dried plums (prunes) vs. psyllium for constipation, Aliment. Pharmacol. Ther., 2011, 33, 822-828.

69 L. J. Cheskin, J. Margolick, S. Kahan, A. H. Mitola, K. H. Poddar, T. Nilles, S. Kolge, F. Menendez, M. Ridoré, S. J. Wang, J. Chou and E. Carlson, Effect of nutritional supplements on immune function and body weight in malnourished adults, Nutr. Metab. Insights, 2010, 3, 2535.

70 S. W. Chey, W. D. Chey, K. Jackson and S. Eswaran, Exploratory Comparative Effectiveness Trial of Green Kiwifruit, Psyllium, or Prunes in US Patients With 
Chronic Constipation, Am. J. Gastroenterol., 2021, 116(6), 1304-1312.

71 L. Howarth, Y. Petrisko, A. Furchner-Evanson, T. Nemoseck and M. Kern, Snack selection influences nutrient intake, triglycerides, and bowel habits of adult women: a pilot study, J. Am. Diet. Assoc., 2010, 110, 13221327.

72 E. Lever, J. Cole, S. M. Scott, P. W. Emery and K. Whelan, Systematic review: the effect of prunes on gastrointestinal function, Aliment. Pharmacol. Ther., 2014, 40, 750-758.

73 E. Lever, S. M. Scott, P. Louis, P. W. Emery and K. Whelan, The effect of prunes on stool output, gut transit time and gastrointestinal microbiota: A randomised controlled trial, Clin. Nutr., 2019, 38, 165-173.

74 E. A. Lucas, L. J. Hammond, V. Mocanu, A. B. Arquitt, A. Trolinger, D. A. Khalil, B. J. Smith, D. Y. Soung, B. P. Daggy and B. H. Arjmandi, Daily Consumption of Dried Plum by Postmenopausal Women Does Not Cause Undesirable Changes in Bowel Function, J. Appl. Res., 2004, 4(1), 37-43.

75 L. Piirainen, K. Peuhkuri, K. Bäckström, R. Korpela and S. Salminen, Prune juice has a mild laxative effect in adults with certain gastrointestinal symptoms, Nutr. Res., 2007, 27, 511-513.

76 L. F. Tinker, B. O. Schneeman, P. A. Davis, D. D. Gallaher and C. R. Waggoner, Consumption of prunes as a source of dietary fiber in men with mild hypercholesterolemia, Am. J. Clin. Nutr., 1991, 53, 1259-1265.

77 G. D. Noratto, J. F. Garcia-Mazcorro, M. Markel, H. S. Martino, Y. Minamoto, J. M. Steiner, D. Byrne, J. S. Suchodolski and S. U. Mertens-Talcott, CarbohydrateFree Peach (Prunus persica) and Plum (Prunus salicina) Juice Affects Fecal Microbial Ecology in an Obese Animal Model, PLoS One, 2014, 9, e101723.

78 C. Hidalgo-Cantabrana, S. Delgado, L. Ruiz, P. RuasMadiedo, B. Sánchez and A. Margolles, Bifidobacteria and Their Health-Promoting Effects, Microbiol. Spectrum, 2017, 5, DOI: 10.1128/microbiolspec.BAD-0010-2016.

79 M. Tamura, Y. Ohnishi, T. Kotani and N. Gato, Effects of new dietary fiber from Japanese Apricot (Prunus mume Sieb. et Zucc.) on gut function and intestinal microflora in adult mice, Int. J. Mol. Sci., 2011, 12, 2088-2099.

80 J. F. Garcia-Mazcorro, N. N. Lage, S. Mertens-Talcott, S. Talcott, B. Chew, S. E. Dowd, J. R. Kawas and G. D. Noratto, Effect of dark sweet cherry powder consumption on the gut microbiota, short-chain fatty acids, and biomarkers of gut health in obese $\mathrm{db} / \mathrm{db}$ mice, PeerJ, 2018, 6, e4195.

81 Integrated Taxonomic Information System (ITIS), http:// www.itis.gov., (accessed 5 August, 2020).

82 V. P. Venancio, H. Kim, M. A. Sirven, C. D. Tekwe, G. Honvoh, S. T. Talcott and S. U. Mertens-Talcott, Polyphenol-rich Mango (Mangifera indica L.) Ameliorate Functional Constipation Symptoms in Humans beyond Equivalent Amount of Fiber, Mol. Nutr. Food Res., 2018, 62, e1701034.
83 M. D. L. García-Magaña, H. S. García, L. A. Bello-Pérez, S. G. Sáyago-Ayerdi and M. Mata-Montes de Oca, Functional properties and dietary fiber characterization of mango processing by-products (Mangifera indica L., cv Ataulfo and Tommy Atkins), Plant Foods Hum. Nutr., 2013, 68(3), 254-258.

84 A. Verma and R. Mogra, Psyllium (Plantago ovata) Husk: A Wonder Food for Good Health, Int. J. Sci. Res., 2015, 4, 1581-1585.

85 V. Neveu, J. Perez-Jiménez, F. Vos, V. Crespy, L. du Chaffaut, L. Mennen, C. Knox, R. Eisner, J. Cruz, D. Wishart and A. Scalbert, Phenol-Explorer: an online comprehensive database on polyphenol contents in foods, Database, 2010, 2010, bap024.

86 L. Bravo, F. Saura-Calixto and I. Goni, Effects of dietary fibre and tannins from apple pulp on the composition of faeces in rats, Br. J. Nutr., 1992, 67, 463-473.

87 T. R. Licht, M. Hansen, A. Bergström, M. Poulsen, B. N. Krath, J. Markowski, L. O. Dragsted and A. Wilcks, Effects of apples and specific apple components on the cecal environment of conventional rats: role of apple pectin, BMC Microbiol., 2010, 10, 13.

88 S. Elkahoui, C. E. Levin, G. E. Bartley, W. Yokoyama and M. Friedman, Levels of Fecal Procyanidins and Changes in Microbiota and Metabolism in Mice Fed a High-Fat Diet Supplemented with Apple Peel, J. Agric. Food Chem., 2019, 67, 10352-10360.

89 A. Koutsos, M. Lima, L. Conterno, M. Gasperotti, M. Bianchi, F. Fava, U. Vrhovsek, J. A. Lovegrove and K. M. Tuohy, Effects of Commercial Apple Varieties on Human Gut Microbiota Composition and Metabolic Output Using an In Vitro Colonic Model, Nutrients, 2017, 9(6), 533.

90 J. D. D. Tamokou, A. T. Mbaveng and V. Kuete, in Medicinal Spices and Vegetables from Africa - Therapeutic Potential Against Metabolic, Inflammatory, Infectious and Systemic Diseases, ed. V. Kuete, Academic Press, 2017, pp. 207-237.

91 A. Costabile, G. E. Walton, G. Tzortzis, J. Vulevic, D. Charalampopoulos and G. R. Gibson, Effects of orange juice formulation on prebiotic functionality using an in vitro colonic model system, PLoS One, 2015, 10, e0121955.

92 E. Brasili, N. M. A. Hassimotto, F. Del Chierico, F. Marini, A. Quagliariello, F. Sciubba, A. Miccheli, L. Putignani and F. Lajolo, Daily Consumption of Orange Juice from Citrus sinensis L. Osbeck cv. Cara Cara and cv. Bahia Differently Affects Gut Microbiota Profiling as Unveiled by an Integrated Meta-Omics Approach, J. Agric. Food Chem., 2019, 67, 1381-1391.

93 J. H. Kim, S. K. Lee and M. C. Joo, Effects and Safety of Aqueous Extract of Poncirus fructus in Spinal Cord Injury with Neurogenic Bowel, J. Evid. Based Complementary Altern. Med., 2016, 2016, 7154616.

94 K. Papoutsis, Q. V. Vuong, J. B. Golding, J. H. Hasperué, P. Pristijono, M. C. Bowyer, C. J. Scarlett and C. E. Stathopoulos, Pretreatment of citrus by-products 
affects polyphenol recovery: a review, Food Rev. Int., 2018, 34, 770-795.

95 P. Tu, X. Bian, L. Chi, B. Gao, H. Ru, T. J. Knobloch, C. M. Weghorst and K. Lu, Characterization of the Functional Changes in Mouse Gut Microbiome Associated with Increased Akkermansia muciniphila Population Modulated by Dietary Black Raspberries, ACS Omega, 2018, 3, 10927-10937.

96 J. Gu, J. M. Thomas-Ahner, K. M. Riedl, M. T. Bailey, Y. Vodovotz, S. J. Schwartz and S. K. Clinton, Dietary Black Raspberries Impact the Colonic Microbiome and Phytochemical Metabolites in Mice, Mol. Nutr. Food Res., 2019, 63, e1800636.

97 D. Shin, K. S. Che, H. R. Choi, S. J. Lee, S. W. Gim, G. T. Kwon, H. T. Lee, Y. C. Song, K. J. Kim, H. S. Kong and J. W. Kwon, Bioactive and pharmacokinetic characteristics of pre-matured black raspberry, rubus occidentalis, Ital. J. Food Sci., 2018, 30, 428-439.

98 G. Istas, E. Wood, M. Le Sayec, C. Rawlings, J. Yoon, V. Dandavate, D. Cera, S. Rampelli, A. Costabile, E. Fromentin and A. Rodriguez-Mateos, Effects of aronia berry (poly)phenols on vascular function and gut microbiota: a double-blind randomized controlled trial in adult men, Am. J. Clin. Nutr., 2019, 110, 316-329.

99 K. O’Connor, M. Morrissette, P. Strandwitz, M. Ghiglieri, M. Caboni, H. Liu, C. Khoo, A. D'Onofrio and K. Lewis, Cranberry extracts promote growth of Bacteroidaceae and decrease abundance of Enterobacteriaceae in a human gut simulator model, PLoS One, 2019, 14, e0224836.

100 S. Lee, K. I. Keirsey, R. Kirkland, Z. I. Grunewald, J. G. Fischer and C. B. de La Serre, Blueberry Supplementation Influences the Gut Microbiota, Inflammation, and Insulin Resistance in High-Fat-DietFed Rats, J. Nutr., 2018, 148, 209-219.

101 A. Lacombe, R. W. Li, D. Klimis-Zacas, A. S. Kristo, S. Tadepalli, E. Krauss, R. Young and V. C. Wu, Lowbush wild blueberries have the potential to modify gut microbiota and xenobiotic metabolism in the rat colon, PLoS One, 2013, 8, e67497.

102 U. D. Wankhade, Y. Zhong, O. P. Lazarenko, S. V. Chintapalli, B. D. Piccolo, J. R. Chen and K. Shankar, Sex-Specific Changes in Gut Microbiome Composition following Blueberry Consumption in C57BL/6J Mice, Nutrients, 2019, 11(2), 313.

103 S. Vendrame, S. Guglielmetti, P. Riso, S. Arioli, D. KlimisZacas and M. Porrini, Six-week consumption of a wild blueberry powder drink increases bifidobacteria in the human gut, J. Agric. Food Chem., 2011, 59, 12815-12820.

104 G. Jakobsdottir, N. Blanco, J. Xu, S. Ahrné, G. Molin, O. Sterner and M. Nyman, Formation of short-chain Fatty acids, excretion of anthocyanins, and microbial diversity in rats fed blackcurrants, blackberries, and raspberries, J. Nutr. Metab., 2013, 2013, 202534.

105 T. L. Parker, X. H. Wang, J. Pazmiño and N. J. Engeseth, Antioxidant capacity and phenolic content of grapes, sundried raisins, and golden raisins and their effect on ex vivo serum antioxidant capacity, J. Agric. Food Chem., 2007, 55, 8472-8477.

106 S. Rodríguez-Costa, A. Cardelle-Cobas, P. Roca-Saavedra, J. J. Porto-Arias, J. M. Miranda and A. Cepeda, In vitro evaluation of the prebiotic effect of red and white grape polyphenolic extracts, J. Physiol. Biochem., 2018, 74, 101110.

107 K. Tebib, P. Besançon and J.-M. Rouanet, Effects of dietary grape seed tannins on rat cecal fermentation and colonic bacterial enzymes, Nutr. Res., 1996, 16, 105-110.

108 J. Yamakoshi, S. Tokutake, M. Kikuchi, Y. Kubota, H. Konishi and T. Mitsuoka, Effect of ProanthocyanidinRich Extract from Grape Seeds on Human Fecal Flora and Fecal Odor, Microb. Ecol. Health Dis., 2001, 13, 25-31.

109 G. Mandalari, S. Chessa, C. Bisignano, L. Chan and A. Carughi, The effect of sun-dried raisins (Vitis vinifera L.) on the in vitro composition of the gut microbiota, Food Funct., 2016, 7, 4048-4060.

110 A. T. Wijayabahu, S. G. Waugh, M. Ukhanova and V. Mai, Dietary raisin intake has limited effect on gut microbiota composition in adult volunteers, Nutr. J., 2019, 18, 14.

111 G. A. Spiller, J. A. Story, T. A. Lodics, M. Pollack, S. Monyan, G. Butterfield and M. Spiller, Effect of sundried raisins on bile acid excretion, intestinal transit time, and fecal weight: a dose-response study, J. Med. Food, 2003, 6, 87-91.

112 V. Nash, C. S. Ranadheera, E. N. Georgousopoulou, D. D. Mellor, D. B. Panagiotakos, A. J. McKune, J. Kellett and N. Naumovski, The effects of grape and red wine polyphenols on gut microbiota - A systematic review, Food Res. Int., 2018, 113, 277-287.

113 K. Tebib, J. M. Rouanet and P. Besançon, Effect of grape seed tannins on the activity of some rat intestinal enzyme activities, Enzyme Protein, 1994, 48, 51-60.

114 L. Drummond, The composition and nutritional value of kiwifruit, Adv. Food Nutr. Res., 2013, 68, 33-57.

115 S. G. Parkar, D. Rosendale, G. Paturi, T. D. Herath, H. Stoklosinski, J. E. Phipps, D. Hedderley and J. Ansell, In vitro utilization of gold and green kiwifruit oligosaccharides by human gut microbial populations, Plant Foods Hum. Nutr., 2012, 67, 200-207.

116 P. Blatchford, K. L. Bentley-Hewitt, H. Stoklosinski, T. McGhie, R. Gearry, G. Gibson and J. Ansell, In vitro characterisation of the fermentation profile and prebiotic capacity of gold-fleshed kiwifruit, Benefic. Microbes, 2015, 6, 829-839.

117 J. A. Monro and G. Paturi, Kiwifruit Skin and Flesh Contributions to Fecal Bulking and Bacterial Abundance in Rats, Plant Foods Hum. Nutr., 2020, 75, 525-531.

118 A. Alim, T. Li, T. Nisar, D. Ren, Y. Liu and X. Yang, Consumption of two whole kiwifruit (Actinide chinensis) per day improves lipid homeostasis, fatty acid metabolism and gut microbiota in healthy rats, Int. J. Biol. Macromol., 2020, 156, 186-195. 
119 P. Blatchford, H. Stoklosinski, S. Eady, A. Wallace, C. Butts, R. Gearry, G. Gibson and J. Ansell, Consumption of kiwifruit capsules increases Faecalibacterium prausnitzii abundance in functionally constipated individuals: a randomised controlled human trial, J. Nutr. Sci., 2017, 6, e52.

120 A. O. Chan, G. Leung, T. Tong and N. Y. Wong, Increasing dietary fiber intake in terms of kiwifruit improves constipation in Chinese patients, World J. Gastroenterol., 2007, 13, 4771-4775.

121 C. C. Chang, Y. T. Lin, Y. T. Lu, Y. S. Liu and J. F. Liu, Kiwifruit improves bowel function in patients with irritable bowel syndrome with constipation, Asia Pac. J. Clin. Nutr., 2010, 19, 451-457.

122 V. Wilkinson-Smith, N. Dellschaft, J. Ansell, C. Hoad, L. Marciani, P. Gowland and R. Spiller, Mechanisms underlying effects of kiwifruit on intestinal function shown by MRI in healthy volunteers, Aliment. Pharmacol. Ther., 2019, 49, 759-768.

123 R. Wilson, J. Willis, R. B. Gearry, A. Hughes, B. Lawley, P. Skidmore, C. Frampton, E. Fleming, A. Anderson, L. Jones, G. W. Tannock and A. C. Carr, SunGold Kiwifruit Supplementation of Individuals with Prediabetes Alters Gut Microbiota and Improves Vitamin C Status, Anthropometric and Clinical Markers, Nutrients, 2018, 10(7), 895.

124 K. Rtibi, S. Selmi, K. Saidani, D. Grami, M. Amri, H. Sebai and L. Marzouki, Reverse Effect of Opuntia ficus-indica L. Juice and Seeds Aqueous Extract on Gastric Emptying and Small-Bowel Motility in Rat, J. Food Sci., 2018, 83, 205-211.

125 K. Rtibi, S. Selmi, D. Grami, M. Amri, H. Sebai and L. Marzouki, Opposite Effect of Opuntia ficus-indica L. Juice Depending on Fruit Maturity Stage on Gastrointestinal Physiological Parameters in Rat, J. Med. Food, 2018, 21, 617-624.

126 P. Khuituan, S. K-da, K. Bannob, F. Hayeeawaema, S. Peerakietkhajorn, C. Tipbunjong, S. Wichienchot and N. Charoenphandhu, Prebiotic oligosaccharides from dragon fruits alter gut motility in mice, Biomed. Pharmacother., 2019, 114, 108821.
127 K. Mahattanatawee, J. A. Manthey, G. Luzio, S. T. Talcott, K. Goodner and E. A. Baldwin, Total antioxidant activity and fiber content of select Florida-grown tropical fruits, J. Agric. Food Chem., 2006, 54, 7355-7363.

128 H. Y. Lee, J. H. Kim, H. W. Jeung, C. U. Lee, D. S. Kim, B. Li, G. H. Lee, M. S. Sung, K. C. Ha, H. I. Back, S. Y. Kim, S. H. Park, M. R. Oh, M. G. Kim, J. Y. Jeon, Y. J. Im, M. H. Hwang, B. O. So, S. J. Shin, W. H. Yoo, H. R. Kim, H. J. Chae and S. W. Chae, Effects of Ficus carica paste on loperamide-induced constipation in rats, Food Chem. Toxicol., 2012, 50, 895-902.

129 H. I. Baek, K. C. Ha, H. M. Kim, E. K. Choi, E. O. Park, B. H. Park, H. J. Yang, M. J. Kim, H. J. Kang and S. W. Chae, Randomized, double-blind, placebo-controlled trial of Ficus carica paste for the management of functional constipation, Asia Pac. J. Clin. Nutr., 2016, 25, 487-496.

130 C. Picard, J. Fioramonti, A. Francois, T. Robinson, F. Neant and C. Matuchansky, Review article: bifidobacteria as probiotic agents - physiological effects and clinical benefits, Aliment. Pharmacol. Ther., 2005, 22, 495-512.

131 S. Miquel, R. Martín, O. Rossi, L. G. Bermúdez-Humarán, J. M. Chatel, H. Sokol, M. Thomas, J. M. Wells and P. Langella, Faecalibacterium prausnitzii and human intestinal health, Curr. Opin. Microbiol., 2013, 16, 255261.

132 C. S. Reigstad, C. E. Salmonson, J. F. Rainey 3rd, J. H. Szurszewski, D. R. Linden, J. L. Sonnenburg, G. Farrugia and P. C. Kashyap, Gut microbes promote colonic serotonin production through an effect of shortchain fatty acids on enterochromaffin cells, FASEB J., 2015, 29, 1395-1403.

133 R. Soret, J. Chevalier, P. De Coppet, G. Poupeau, P. Derkinderen, J. P. Segain and M. Neunlist, Short-chain fatty acids regulate the enteric neurons and control gastrointestinal motility in rats, Gastroenterology, 2010, 138, 1772-1782.

134 P. E. Squires, R. D. Rumsey, C. A. Edwards and N. W. Read, Effect of short-chain fatty acids on contractile activity and fluid flow in rat colon in vitro, Am. J. Physiol., 1992, 262, G813-G817. 